\title{
Designs Guided by Ideology
}

\author{
Ying Han \\ Nanshan University \\ Yantai, Shandong Province, China
}

\begin{abstract}
Throughout the history of design, human beings have gained deeper and deeper understanding of natural and social relations. With the advancement of technologies and skills, products designed have taken a new appearance of attracting diversity, which facilitate the development of society. This paper, taking the relation between ideology and design as a point of penetration, explores the way to better serve the mass depending on the good designs under a new social background.
\end{abstract}

\section{Keywords - ideology; visual arts; control design}

\section{INTRODUCTION}

Design activity appeared long before with formation of the human ideology. Since its formation, human beings have constantly been seeking external forces to change their living environment. For example, Karl Marx wrote in Chapter 5 Volume I of his Das Kapital about the difference between human work and animal work, "The achievements of human work have already existed in people's mind. Through work, human beings can not only change the nature of an existing object, but also realize what they have envisioned before the work." 1 Therefore, influenced by the ideology, human beings use their ability of design to transform natural objects into artificial ones which cater to the human need. With the changing of natural and social environments, people's thoughts also underwent many changes. The designs, similarly, have also gained development under the changing ideology.

\section{FROM “BORROWED DESIGN" TO "CONTROLLING DESIGN"}

\section{A. The Borrowed design}

The history of human beings started from their conscious work while design began through the way of borrowing "things" from others. The word "borrowing" can be explained from the perspective of both function and ideology.

In terms of function, human beings change the nature in purpose of meeting more needs of life. In this case, the products designed by them are regarded as the extension of human organs. They are borrowed mostly from the animals. Many of the human organs, in fact, cannot function as strongly and sensitively as those of animals. For example, the dogs' sense of smell, eyesight of the eagle, speed of the panther, the bats' hearing etc. are all far better than human's. Nevertheless, human beings have quite developed brains which can utilize the external things to help cover their shortages and allow them to seek development. In the Stone Age, human beings applied stones to fallen trees and animal bones to make tools, which are all iron evidences for human beings' wisdom.

From the perspective of ideology, human beings applied different symbols to represent their values and beliefs. As mentioned above, many of the human organs cannot function as sensitively as those of animals. But after the initial borrowings they had made from the animals, they have gained more knowledge the nature. Hence, they started to explore more effective ways to strengthen themselves, aiming at conquering nature. They began to admire those that were stronger and more sacred than them and hoped that these things could give them inspiration to realize the dream of conquering. The ups and downs of totem illustrated a very good example. The culture of totem began at the middle of the Old Stone Age and flourished at the end of the same Age. When it came to the New Stone Age, it began to decline. That's because in a society where productivity is very low, human beings all admired the mystery of nature very much. Therefore, they created a certain totem, hoping that strong features of the plants and animals could make them stronger. However, during the New Stone Age, human beings gradually conquered the animals and knew more about the nature. Animal husbandry appeared soon after, demonstrating that animals were having weakening advantage than before. Therefore, the culture of totem fell. It was them replaced by some ideally processed and deific symbols which combined almost all the strength of the animals in one. The Chinese dragon can best illustrate such fact. The image of the dragon in the old legend was that: it has the body of a snake, limbs of a beast, fur of a horse, tale of a mane, horn of a deer, paws of a dog and scale and barbell of a fish, which meant that the old Huaxia tribe with the snake as the totem would conquer and merge with other tribes in the future. Namely, the snake would gain strength from other totems to finally become a dragon. Another example, the creation of the Sphinx in Egypt aimed at seeking the protection of the immortals and holy beasts. Apart from those single designs, many symbolic patterns have appeared in the designs before the Industrial Revolution. The higher the level of productivity, the stronger the need to seek protection will be. Consequently, the decorating crafts and techniques became ever more complicated, which accords with the old requirements in Chinese traditional design art--- "Figure will be interested in, Italy will be lucky." 


\section{B. The controlling design}

With the emergence of the Industrial Revolution, many used-to-be mysterious phenomena's have got scientific explanations. Thus, people gain more knowledge about nature. The way of production inevitably has changed from the simple "borrowing design" to "mechanized production" which utilizes the interaction between human beings and nature. Gradually, the manual labor was released. The form of design in the industrial environment, therefore, started to take controlling design as the principal.

In terms of design and production, such features are mainly reflected in the control of human-nature relations. The steam engine in the Industrial Revolution, for example, transforms natural steam power into mechanical work which has massively liberated the human power. The process of transformation, unlike the past one which took designed products as the extension of human body, embodies more of human beings' controlling power over their relation to nature. In such relations of production, which prefers controlling and complying with nature, human wills prevails manual work. Moreover, the rapid development of science and technology, the coming of the Information Revolution as well as the popular artificial intelligence have made such kind of controlling design based on human wills more overwhelming.

In the terms of ideology, such controlling designs have also brought changes to the form of design. The appearance of mechanization reflects that human kind began to seek for essence instead of taking the appearance for granted. As a result, productivity was improved. More importantly, the mysterious veil covering the divine power was revealed, leading to substantive social structure changes. As a result, people's interest on human rights has also increased greatly due to their evaluated ability, which reflected their increasing need for more scope of control. From a macro perspective, the designs in such a transitional period can be concluded as "from 'design for deity' to 'design for human'"

Through comparison between totems from primitive tribes and that of modern designs, we can find much difference. The design of primitive totems was relatively more concrete and complicated with specific denotation to a type of plant, animal or phenomenon. Apart from functioning as a symbol for identity, the totems tended to apply the power of ideology to seek psychological protection. On the contrary, the modern design becomes more symbolic, simple and easy to recognize as it advances. It is kind of the distillation and mark of the human being's mental needs. Such designs are equally easy to accept and control when the human brain processes it. Similarly, the appearance design in ancient times and at present varies greatly. For instance, in the later period of the New Stone Age, ornamentations with patterns of human faces or animal faces were quite popular in the Liangzhu Culture. Those faces are not genial and delicate at all. But such ugly and hideous faces can show the charm of power too. We can see that people in this period were still confronting with the external living environment. They still need the external power to overcome natural disasters. Contrarily, the modern designs tend to be simple and childish like children with big heads in Yoshitomo
Nara's (Japanese artist) works. The modern concept of "less is more" also testifies that trend. Products designed by such concepts are equally easy to be accepted and controlled.

Certainly, the world of design is very much diverse. Designs featuring simplicity cannot represent the general trend of designing. However, with the rapid development of smart technologies, people are focusing more and more on the user-centered-designs (UCD). The content of designs caters more deeply to peoples thought and mental feelings, which makes the controlling design more prominent.

\section{DISCUSSION ON DESIGN BASED ON THE THEORY OF YIN AND YANG.}

Design occurred after the appearance of human consciousness, under which popped up the products that cater to the human beings' demand. The interrelations between human consciousness and the natural objects exist just like the relationship between "yin" and "yang" in Tai ji diagram. The theory of yin and yang holds that everything in the universe has two opposites but united aspects. The two aspects ---yin and yang are bound together as parts of a mutual whole. They interact with each other and cause the change and movement of everything in the world. The ancient people called such interaction as "immortal movement". Here we apply the thought pattern of the theory of yin and yang to interpret the relationship between ideology and products when we design. In the Book of Changes writes "CHIEN (yang) is the beginning while KUN (yin) forms concrete objects." In other words, "CHIEN" and "KUN" is the origin of everything. CHIEN form the frame and KUN provides the materials. The two interact with each other when all things on earth come into being. Both are very important. However, CHIEN is the principal aspect of the contradiction because we can put in concrete materials only when the frame is built. When it comes to the relation between material and ideology, ideology is yang and material is yin. Then the relation is easy to see.

On one hand, different ideologies breed different material forms. Different social groups have different standards for beauty. For example, Mulsi women living in south-western Ethiopia put plates into their mouths from the age of ten. The larger the plate in their mouth, the more beautiful and valuable they will be considered by their clansmen. Such aesthetic standards are unacceptable in the mainstream concept of beauty of the modern society. Psychologists explain such phenomenon with the following reasons: Human beings are born with the instinct of autonomy which is more obvious in the primitive nations. The underlying purpose of autonomy is to emphasize their existence and distinctiveness so that they will not be forgotten by history. It is the influence from such ideology that leads to entirely different aesthetic standards and life styles of primitive nations. Similarly, from the perspective of macro history, the styles of design arts before the Industrial Revolution mainly cater to the tastes of the monarchy. Later, with the ever increasing democracy in people's minds, special, mixed, multi-style designs appeared in succession. Design styles in this period are greatly all-inclusive and diversified. Meanwhile, in terms of the theory of yin and yang, both of 
yin and yang exist in pair with each one indispensable to the other. Therefore, we can conclude that the objects created which follow the human wills can also be deemed as the carrier of ideology. That can be embodied in many designed works like the ancient totem volume and the modern mark designs. Besides, the methods used in the language of Television works such as montages are also revealing human beings' inner world.

On the other hand, different material environments may also pose certain influence on human ideology. For example, after WWII, the housing shortage has prevailed America and the European countries. In such urgent situations, "divergence on issue of the architect style which had troubled many artists found solution overnight. Due to the pressure of housing, people all turned to the modernism......As a result; modern architectural style rapidly took place of the classical one and got popularity among these countries. It has later grown into a nationalism style."3 In the above case, restricted by lack of material, human kind has to reduce their demand for mental satisfaction and accept the minimalist style. In the process of adaption, people became more and more interested in it, which facilitated its popularity around the world. Moreover, modern designers may change human beings' behaviors through putting thoughts and values in their works, thus changing people's ideology. For instance, "The Japanese designer Shigeru Ban redesigned the toilet paper into the shape of a cuboid, aiming to make it harder to get. Such kind of design will not only largely save the usage of toilet paper, but also expressively advocate people to be abstemious. "4

We can see from the above examples that: human ideology and designed works are greatly interrelated, which makes the task more arduous for the modern designers. A good design should both reflect the existing problems and take the interaction between the designed work and the user. In that case, the modern designers should be more considerate when designing as well as be more responsible for the works they have designed and will design.

\section{THE POWER OF DESIGN}

All forms, whether material or ideological, have certain power which is constantly in transition. For example, in the later period of the New Stone Age, western and northern Europe, northern Africa as well as Asian countries like India all witnessed the emergence of megalithic culture. Those megaliths may have different functions. But through the huge contrast of size between them and the human body, we can see that the mental power of seeking a safe place and protection under a relatively poor condition is transformed into the external form. In the modern society when artificial intelligence gains rapid advancement, such transition occurs even more frequently from mental power to material or we can say that the power is outputted through the form of material. The invention of 3-D printer accelerates such transition.

It should be noticed that, in the environment where artificial materials are extremely abundant, the management of such material will consume much of peoples' mental power. This will, to some extent, weaken peoples' development of identity, with the spirit being hijacked by materials (restricted by materials). Hence, Mr. Kenyahara mentioned the word "emotion driven" in his book Design of Design, aiming at calling back human beings' original recognition from the perspective of design.

\section{REFERENCE}

[1] Zhu ming, Jing lei. The History of Design[M].Shandong Fine Arts Publishing House, Shangdong,2004.11

[2] Xiong Yihong. Chinese History in Diagrams [M]. Zhongzhou Ancient Books Publishing House, Zhengzhou, 2011.15

[3] Wang Qijun. Post-modern Stories [M]. China Machine Press, Shanghai, 2008.6

[4] Kenyahara. Design of Design [M]. Guangxi Normal University Press, Guangxi, 2011.28 